\title{
Economic Analysis of Different Nuclear Fuel Cycle Options
}

\author{
Won Il Ko and Fanxing Gao \\ Korea Atomic Energy Research Institute, Yuseong, Daejeon 305-353, Republic of Korea \\ Correspondence should be addressed to Won Il Ko, nwiko@kaeri.re.kr
}

Received 2 February 2012; Accepted 13 April 2012

Academic Editor: Katsuhisa Yamaguchi

Copyright (C) 2012 W. I. Ko and F. Gao. This is an open access article distributed under the Creative Commons Attribution License, which permits unrestricted use, distribution, and reproduction in any medium, provided the original work is properly cited.

\begin{abstract}
An economic analysis has been performed to compare four nuclear fuel cycle options: a once-through cycle (OT), DUPIC recycling, thermal recycling using MOX fuel in a pressurized water reactor (PWR-MOX), and sodium fast reactor recycling employing pyroprocessing (Pyro-SFR). This comparison was made to suggest an economic competitive fuel cycle for the Republic of Korea. The fuel cycle cost (FCC) has been calculated based on the equilibrium material flows integrated with the unit cost of the fuel cycle components. The levelized fuel cycle costs (LFCC) have been derived in terms of mills/kWh for a fair comparison among the FCCs, and the results are as follows: OT 7.35 mills/kWh, DUPIC 9.06 mills/kWh, PUREX-MOX 8.94 mills/kWh, and Pyro-SFR $7.70 \mathrm{mills} / \mathrm{kWh}$. Due to unavoidable uncertainties, a cost range has been applied to each unit cost, and an uncertainty study has been performed accordingly. A sensitivity analysis has also been carried out to obtain the break-even uranium price $(215 \$ / \mathrm{kgU})$ for the Pyro-SFR against the OT, which demonstrates that the deployment of the Pyro-SFR may be economical in the foreseeable future. The influence of pyrotechniques on the LFCC has also been studied to determine at which level the potential advantages of Pyro-SFR can be realized.
\end{abstract}

\section{Introduction}

Economics is an essential criterion to be considered in the future deployment of nuclear power. Today, the cost of electricity from nuclear power plants is, in most cases, highly competitive with other electricity-producing means, and is generally lower in cost than fossil fuel, wind, or solar energy. However, a closer look at nuclear power production brings an insight that the cost varies within a wide range, depending on the nuclear fuel cycle option. With the current trend toward competition in the power market, the option of nuclear fuel cycle is an important determinant in terms of economics.

Four nuclear fuel cycle options can be considered in the foreseeable future under the nuclear power situation in the Republic of Korea: a once-through cycle (OT), DUPIC recycling (DUPIC), thermal recycling using MOX fuel in a PWR (PWR-MOX), and SFR recycling employing pyroprocessing (Pyro-SFR). A comprehensive comparison among the proposed fuel cycle options necessitates an economic analysis for each option based on the material flow estimation. The objective of this work is to provide a systematic cost comparison among these nuclear fuel cycles.
FCC includes a front-end cost and back-end cost as well as costs associated with fuel recycling in the cases of recycling options. An economic analysis of FCC is a subject of great interest, which not only concentrates on the cost differences among these four fuel cycle options but also efficiently avoids the large uncertainties of the Generation IV reactor capital costs.

The levelized cost is a fundamental calculation principle in the energy and power industry. It is particularly appropriate for an estimate of the costs of energy given the various technologies. LFCC has offered an effective indicator for an economic comparison among nuclear fuel cycles and was adopted to compare the four fuel cycle options considered in this study [1].

The material flow is the basis used to obtain the LFCC. There are mainly two models to calculate the material flows [2-5]. One is an equilibrium model, and the other is a dynamic model. The equilibrium model focuses on a batch study with the assumptions that the whole system is in a steady state and that the mass flow as well as electricity production throughout the fuel cycle is in an ideal equilibrium state, which calculates the material flow 
for the production of a certain amount of electricity to obtain the LFCC with reference to unit cost. The dynamic model takes the timing into consideration to simulate a relatively realistic case. The dynamic model offers a better way to simulate the complement process of a fuel cycle, which may take several decades. Comparatively, the equilibrium model enables a clear and direct comparison to suggest which optimized system should be complemented in the future. In particular, while the current research and development of certain technologies such as SFR and pyroprocessing are still underway, an equilibrium model offers a way to avoid large uncertainties of the future development and deployment. In this study, an equilibrium model was therefore built to calculate the material flow on a batch basis. With the unit costs being determined, the cost of each step of the fuel cycle could be obtained as an approach to obtain the LFCC.

The change of each key component due to the uncertainties can result in considerable differences in LFCCs among the fuel cycle scenarios. To take these unavoidable uncertainties into account, a wide range was applied to each unit cost, and the distribution of LFCC was obtained.

\section{Reference Fuel Cycle and Material Flows}

The four fuel cycle options considered in this study are specified by the breakdown structures consisting of a series of components (or steps), as shown in Figure 1. Figure 1(a) describes the OT material flow, which utilizes low-enriched uranium in a PWR without reprocessing of the spent fuels (SFs).

PWR SFs still contain fissile materials, approximately $0.9 \mathrm{w} \% \mathrm{U}-235$ and $0.5 \mathrm{w} \%$ Pu-239, depending on a $3.5 \%$ U-235 enrichment of the initial fuel and a burnup of $35 \mathrm{GWd} / \mathrm{tHM}$, and therefore can be used as the fuel for CANDU reactors after the removal of some fission products (FPs). This PWR-CANDU symbiotic fuel cycle is referred to as DUPIC recycling [6], and the material flow is described in Figure 1(b).

Some $\mathrm{Pu}$ isotopes such as $\mathrm{Pu}-239$ and $\mathrm{Pu}-241$ are fissile, such as U-235, and can be burned using a thermal neutron spectrum. In the PWR-MOX option shown in Figure 1(c), a commercial PUREX technology is used for recovering $U$ and $\mathrm{Pu}$ from the PWR SFs. The reprocessed materials can be fabricated into the mixed oxide (MOX) fuels of $\mathrm{UO}_{2}$ and $\mathrm{PuO}_{2}$ and then loaded into PWRs, while the MOX SFs would be permanently disposed of without further recycling.

A fast reactor utilizes fast neutrons of which a higher energy can burn both U-235 and transuranic elements (TRUs). This aspect makes it possible to transmute the TRUs and extract energy at the same time. In Pyro-SFR recycling shown in Figure 1(d), the PWR SFs are to be reprocessed to obtain TRU-bearing fuels for fast reactors, while the remaining uranium partitioned from the PWR SF would be disposed of as low- and intermediate-level radioactive waste. In this cycle, a sodium-cooled fast reactor (SFR) with a conversion ratio of 0.6067 is considered as the reference fast reactor [7]. Pyroprocessing has been developed to reprocess the oxide fuels discharged from PWRs and to fabricate metallic fuels containing TRU for future SFRs [8]. The metal fueled SFR using alloys of actinides zirconium (AcZr) has a high potential for recycling actinides by being integrated with the pyroprocessing. The TRU fuel after burning in the SFR would be repeatedly reprocessed through pyroprocessing, and the recovered TRUs would be recycled into an SFR to close the fuel cycle. However, it should be noted that practically some nasty TRU isotopes have to be separated and treated as HLW.

The material flow values in Figure 1 were calculated using the equilibrium model based on an output of 1 TWh of electricity, a detailed description of which refers to the previous material flow study [9].

\section{Unit Cost Specification}

The cost data in this paper are presented in 2010 US dollars. Cost data reported at different times were converted into the 2010 values using an escalation rate of $3 \%[10,11]$. It is difficult to estimate the absolute value of each of the components specified in Figure 1 because many uncertainties exist. Therefore, a range of unit cost (i.e., lower bound, nominal value, and upper bound) was applied in regard to these uncertainties. The nominal value refers to the best estimated unit cost. The lower bound means the low cost case, and the upper bound means the high cost case $[5,11]$. It should be noted that the reactor capital and operating costs were not included in the FCC, which was calculated based on the premise introduced by the GEN IV program, in which the targets of the GEN IV reactor capital costs are to be comparable with those of the GEN III reactors [12]. It should be acknowledged that the capital cost taking around $80 \%$ of the total electricity cost [13]. Taking no account of the reactor capital cost, therefore, largely reduces the uncertainty of the SFR, and therefore enhances and emphasizes the contribution of the fuel cycle to the total electricity cost.

The main sources of the unit cost data used in this study were from an OECD/NEA study $[1,5,11]$ and Advanced Fuel Cycle Cost Basis (short for AFCCB) [14-16], and engineering judgments were used when certain data were not available. The summarized data before converting to the 2010 values are listed in Table 1 . Some specifications of the key components are described as follows. It should be noted that the cost difference of MOX fabrication for LWR is dramatically big between the OECD study and AFCCB study. For the OECD 2006 study [5], the cost is $1250 \$ / \mathrm{kgHM}$. However, for the Advanced Fuel Cycle Cost Basis study, the cost is $3200 \$ / \mathrm{kgHM}$ [15]. The difference mainly lies in the technical readiness and the considerations on proliferation resistance (PR) as stated in the AFCCB reports. In our study, we admit the big gaps among different countries concerning the status of MOX fuel fabrication technique. In addition, the PR is definitely important for the future deployment of the fuel cycle, and therefore, the bigger unit cost from the US study was adopted.

3.1. Uranium Price. The uranium cost generally takes around $40 \%$ of the NFCs. The nominal value of the natural uranium 


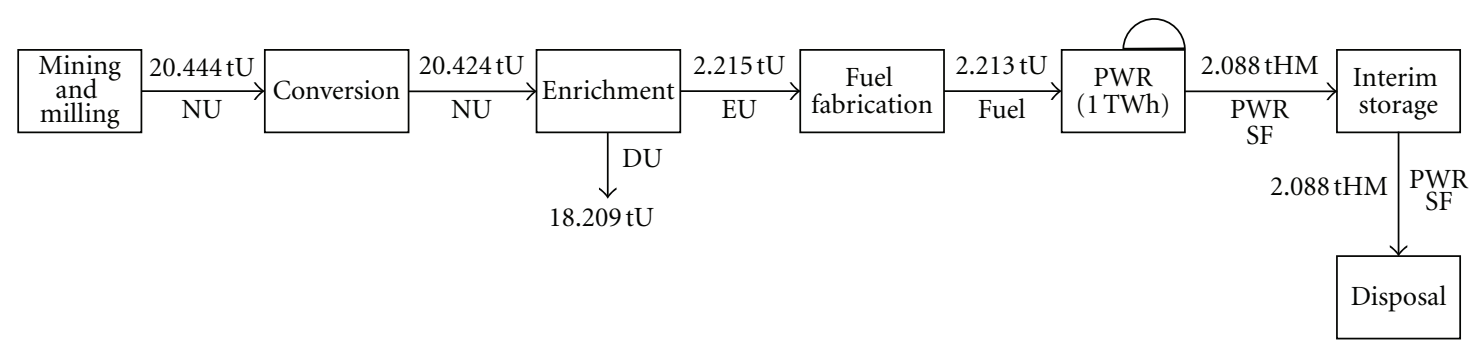

(a) once-through (OT) cycle

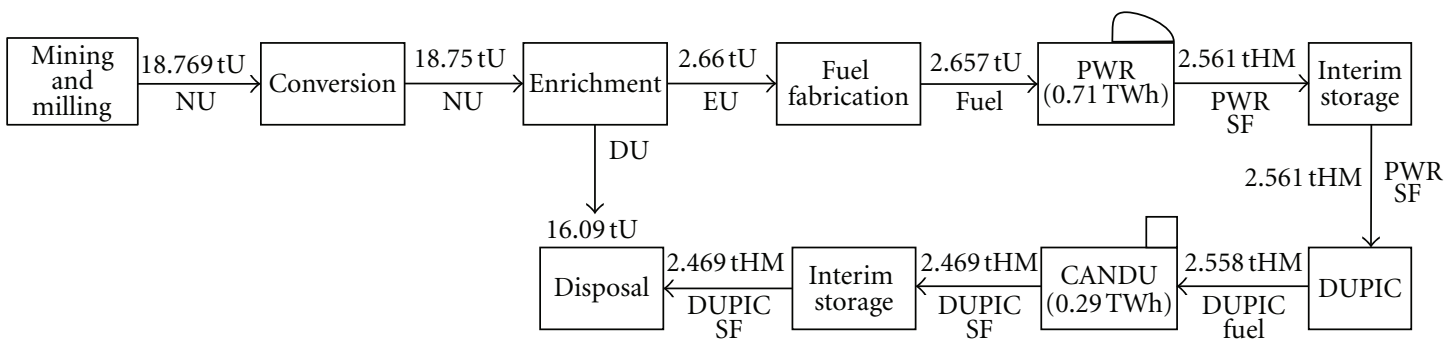

(b) dUPIC recycling

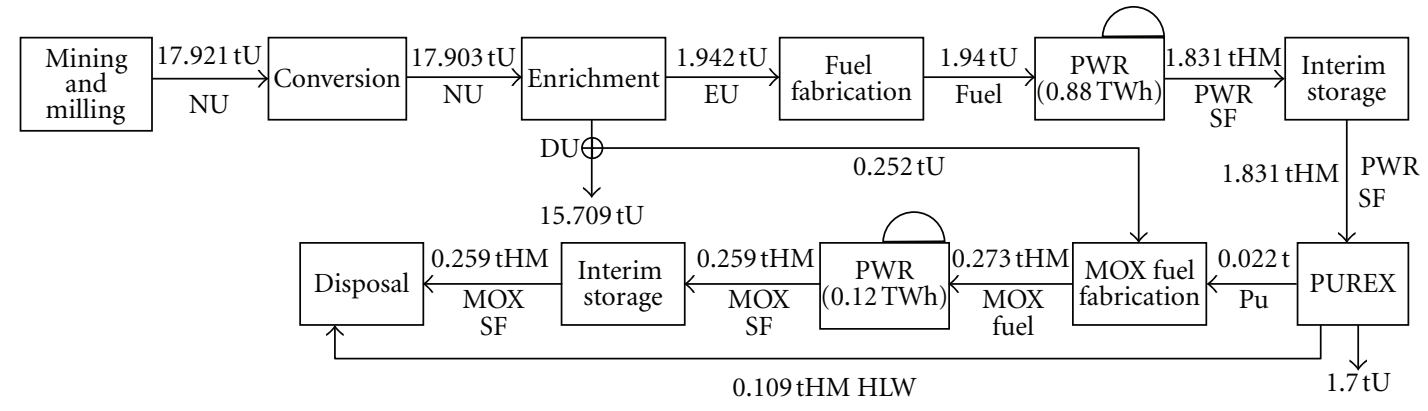

(c) PWR-MOX recycling

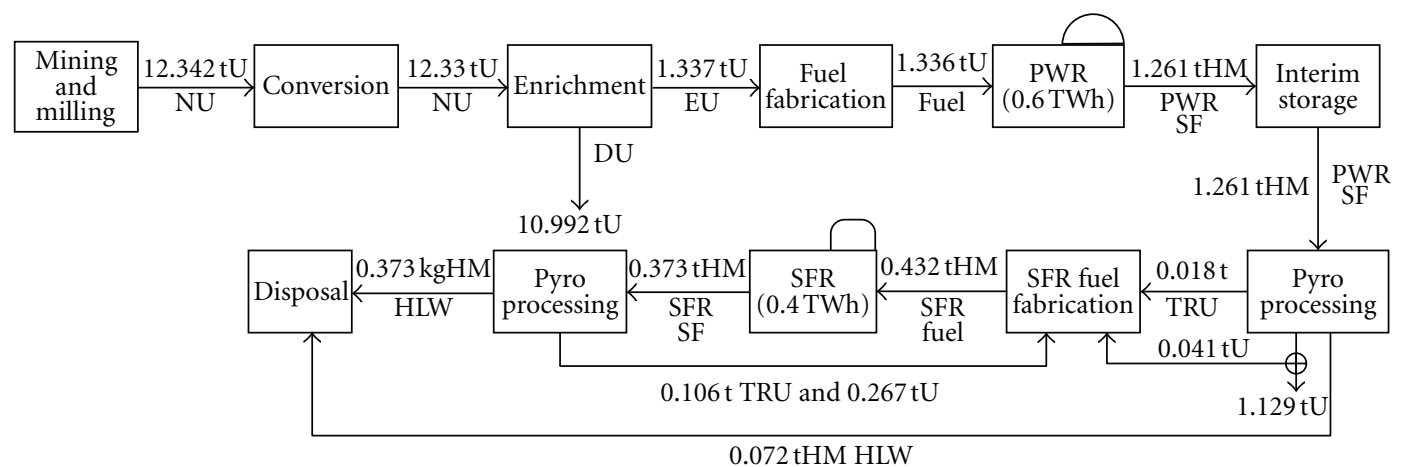

(d) Pyro-SFR recycling

Figure 1: Main components in the nuclear fuel cycles.

price $(158 \$ / \mathrm{kgU})$ was from the monthly average price of December 2010 [17]. The upper bound value of the uranium price was based on the spot price of the historical peak value of June 2007, as shown in Figure 2 [17], which was much higher than the reference data of OECD/NEA and AFCCB. It is challenging to project the future uranium price due to the complexity of the price determinants, such as supply and demand. The uranium price reported in AFCCB was higher than those published by OECD/NEA in 2006. AFCCB reported the uranium price to be a low cost of $50 \$ / \mathrm{kgU}$, nominal cost of $100 \$ / \mathrm{kgU}$, and high cost of $150 \$ / \mathrm{kgU}$ in April 2007 (based on the values at 2007), but in March 2008, it was reported as a low cost of $25 \$ / \mathrm{kgU}$, nominal cost of $60 \$ / \mathrm{kgU}$, and high cost of $240 \$ / \mathrm{kgU}$ (based on the values at 2007), respectively. However, these costs were changed into a low cost of $30 \$ / \mathrm{kgU}$, nominal cost of $75 \$ / \mathrm{kgU}$, and high cost 
TABLE 1: Unit costs for nuclear fuel cycle steps.

\begin{tabular}{|c|c|c|c|c|}
\hline Cost items & Units & Low & Nominal & High \\
\hline Uranium & $\$ / \mathrm{kgU}$ & 30 & 158 & 354 \\
\hline Conversion & $\$ / k g U$ & 5 & 12 & 15 \\
\hline Enrichment & $\$ /$ SWU* & 80 & 155 & 180 \\
\hline \multicolumn{5}{|l|}{ Reprocessing } \\
\hline PUREX & $\$ / \mathrm{kgHM}$ & 700 & 800 & 900 \\
\hline Pyro- $\mathrm{UO}_{2}$ & $\$ / \mathrm{kgHM}$ & 500 & 1,500 & 2,500 \\
\hline \multicolumn{5}{|l|}{ Fuel fabrication } \\
\hline $\mathrm{UO}_{2}$ fuel & $\$ / \mathrm{kgHM}$ & 200 & 240 & 300 \\
\hline MOX fuel & $\$ / \mathrm{kgHM}$ & 2,000 & 3,200 & 4,000 \\
\hline DUPIC fuel & $\$ / \mathrm{kgHM}$ & 500 & 700 & 900 \\
\hline Pyro. and SFR metal fuel fab. & $\$ / \mathrm{kgHM}$ & 2,500 & 5,000 & 7,500 \\
\hline \multicolumn{5}{|l|}{ Long-term storage } \\
\hline Depleted U & $\$ / \mathrm{kgHM}$ & 2.6 & 3.6 & 4.6 \\
\hline Reprocessed U & $\$ / \mathrm{kgHM}$ & 2.6 & 3.6 & 40.0 \\
\hline \multicolumn{5}{|l|}{ Transport and storage } \\
\hline DUPIC SF & $\$ / \mathrm{kgHM}$ & 50 & 100 & 250 \\
\hline $\mathrm{UO}_{2} \mathrm{SF}$ & $\$ / \mathrm{kgHM}$ & 105 & 125 & 145 \\
\hline MOX SF & $\$ / \mathrm{kgHM}$ & 145 & 218 & 580 \\
\hline Decay storage & $\$ / \mathrm{kgHM}$ & 10,000 & 22,500 & 35,000 \\
\hline HLW & $\$ / \mathrm{m}^{3}$ & 80,060 & 120,090 & 200,240 \\
\hline \multicolumn{5}{|l|}{ Disposal } \\
\hline \multicolumn{5}{|l|}{ Packaging } \\
\hline $\mathrm{UO}_{2} \mathrm{SF}$ & $\$ / \mathrm{kg}$ & 100 & 200 & 350 \\
\hline DUPIC SF & $\$ / \mathrm{kg}$ & 80 & 150 & 250 \\
\hline MOX SF & $\$ / \mathrm{kg}$ & 200 & 400 & 700 \\
\hline HLW of PUREX & $\$ / \mathrm{m}^{3}$ & 100,000 & 200,000 & 400,000 \\
\hline HLW of others & $\$ / \mathrm{m}^{3}$ & 100,000 & 200,000 & 400,000 \\
\hline Underground cost & $\$ / \mathrm{m}^{3}$ & 600 & 1,200 & 2,000 \\
\hline
\end{tabular}

${ }^{*}$ SWU stands for separative work unit.

of $260 \$ / \mathrm{kgU}$ in December 2009 based on the values of that year. It seems to be obvious that the newer reports suggest a wider range of uranium price.

It is reasonable to doubt the relatively lower prediction of the uranium price. However, the reason for the adoption of the peak value in this study is to enlarge the possible range of the uranium price to better reflect the high uncertainty of the future uranium price.

3.2. Conversion and Enrichment. The nominal price of conversion and the enrichment processes are from the monthly price of December of 2010. Low and high estimates are referred from the OECD/NEA report [5] and the AFCCB reports [14-16]. The high estimated cost of enrichment of OECD/NEA in 2000 is smaller than the spot price based on 2010, and thus an estimated value of $180 \$ / S W U$ was proposed.

3.3. Pyrotechnique Cost. As no commercial experience exists, the unit costs concerning the pyrotechnique for fuel reprocessing are theoretical and estimated using engineering judgments with high uncertainty. Because of the difference

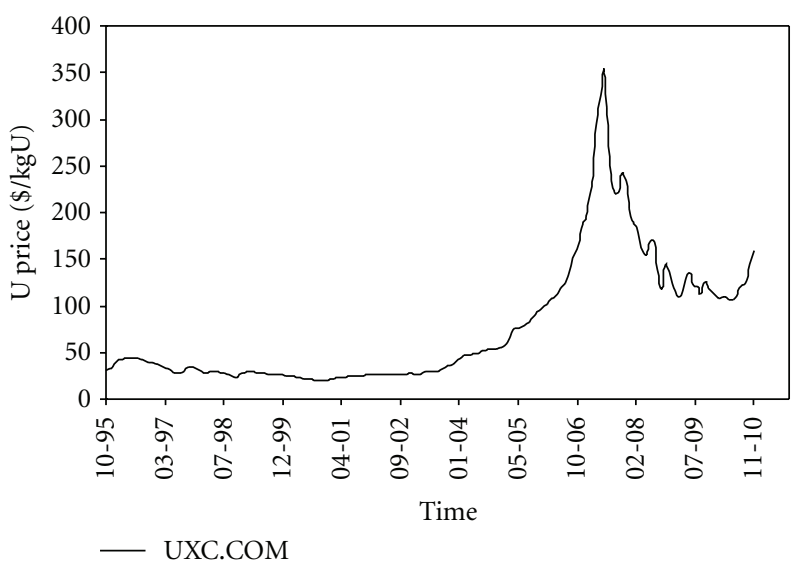

FIgURE 2: Uranium spot prices.

of the fuels treated and a big gap between the material flows evolved, there are two pyrotechnique-related components in the Pyro-SFR recycling scenario. One pyrotechnique treats the PWR SF (named as Pyro- $\mathrm{UO}_{2}$ ), which includes an 
TABLE 2: Lead and lag time of fuel cycle steps.

\begin{tabular}{lcc}
\hline & Fuel cycle process & Lead/lag time (month) \\
\hline & Purchase & 21 \\
\multirow{3}{*}{ Lead time (month) } & Conversion & 18 \\
& Enrichment & 12 \\
& Fabrication & 6 \\
\hline \multirow{3}{*}{ Lag time (month) } & Interim storage & 18 \\
& Reprocessing & 78 \\
& Final disposal & 480 \\
\hline
\end{tabular}

additional electroreduction procedure to reduce the oxide fuels into the metallic fuels, and the other is used for SFR metallic SFs (named as Pyro-Metal-Fab.), which requires a fuel fabrication facility along with it. The unit costs reported in AFCCB 2008 [15] were applied to give a nominal cost of $5000 \$ / \mathrm{kgHM}$ for Pyro-Metal-Fab., and the unit cost of $1500 \$ / \mathrm{kgHM}$ is defined for Pyro- $\mathrm{UO}_{2}$ with regard to the study at the Korea Atomic Energy Research Institute [6, 18]. As the $\mathrm{R} \& \mathrm{D}$ proceeds, more economical cost data might be expected.

3.4. Storage Cost. It is assumed that the interim storage cost consists of two parts: a fixed cost and a variable cost depending on the storage time, which was set for 5 years in this paper $[1,5]$. The decay storage of Cs and Sr which are main heat emitters separated by pyroprocessing, employs a shallow disposal as a low-interim level waste for around 200300 years [18].

\section{Fuel Cycle Cost Calculation}

4.1. Lead and Lag Time. The costs depend on the amount of material or service consumed and the unit price of each component. The payments for the various components of the nuclear fuel cycle are usually made at different moments in time. Each step-cost should be calculated with consideration of its implementation time, starting from the fuel purchase costs and ending to the final disposal costs. It is therefore reasonable to consider the discount rate to compare all the payments at the same time according to the refueling interval plus or minus a lead or lag time as listed in Table 3.

\subsection{Electricity Generation.}

(1) the amount of fuel required by one reactor is estimated based on the reactor parameters, fuel loading per core (MTHM):

$$
\text { Fuel loading per core }=\frac{P \times 100}{\varepsilon \times S H} \text {, }
$$

where $P, S H$, and $\varepsilon$ are the electric power (MWe) of a reactor, the specific heat (MWt/MTHM), and efficiency (\%), respectively;
(2) the annual requirement of fuel (MTHM) is calculated based on fuel burnup and other parameters:

$$
\text { Annual requirement }=\frac{P \times 365 \times C}{\varepsilon \times B U},
$$

where $C$ and $B U$ are the capacity factor (\%) and burnup (MWD/MTHM), respectively;

(3) the electric power generation (MWh) per fuel loading (MTHM) is calculated as follows:

$$
\begin{aligned}
& \text { Power generation per fuel loading } \\
& =24 \times \text { loading }(\text { MTHM }) \times B U \times \varepsilon .
\end{aligned}
$$

The number of PWRs is determined from the equilibrium core ratio mentioned above.

4.3. Fuel Cycle Cost. The amount of fuel passing through a certain step multiplied with the unit cost of the specific material offers the fuel cost of a single step and combined with the additional cost associated with the operation, the overall cost of an operation, namely, the component cost, can be obtained. By summarizing the costs of all the operations involved in an NFC, the overall costs of the NFC can be obtained as listed in Table 3. The method employed for the calculation of FCC is the constant money (levelized life-time cost) method. The levelized unit cost is based on the cash flow of all component costs discounted to the base year. A $5 \%$ discount rate was applied to all unit costs in this paper. To get the total fuel cycle cost, the net present value (NPV) was used, which can be expressed as follows:

$$
\mathrm{NPV}=\sum_{i} F_{i}
$$

4.4. Levelized Fuel Cycle Cost. The LFCC is derived in terms of mills/kWh ( 1 mill equals to $10^{-3} \$$ ) by dividing the NPV of the entire fuel cycle cost by the NPV of the total electricity output over the plant life-time as follows:

$$
\mathrm{LFCC}=\frac{\sum_{i} F_{i}}{E}=\frac{\mathrm{NPV}}{E},
$$

where $E$ is the electric power generated.

4.5. Uncertainty Analysis. The unit costs for each of the components in the fuel cycle were applied using an uncertainty analysis by Monte Carlo simulation using Latin Hypercube extraction mode [19]. It was assumed that the costs of the components would be simulated by triangular distribution. The triangular distribution is a representative nonparametric distribution, which is effective in cases when there is not much data, and the distributions are unknown. The triangular distribution may appear symmetric, rightskewed, or left-skewed according to the expert opinions. The triangular distribution has a very obvious appeal because it is easy to think about the three defining parameters in a fuel cycle economic analysis and to envisage the effect of any changes. 
TABLE 3: Equations used in levelized fuel cycle cost calculation.

\begin{tabular}{|c|c|c|}
\hline $\begin{array}{l}\text { Cost of each fuel } \\
\text { cycle component }\end{array}$ & Cost calculation methods & \\
\hline \multirow[t]{3}{*}{ Uranium } & $F_{U}=M_{f} \cdot f_{U} \cdot P_{U} \cdot(1+r)^{t_{U}}$ & $(4)$ \\
\hline & $M_{f}=M_{p} \cdot\left[\left(e_{p}-e_{t}\right) /\left(e_{f}-e_{t}\right)\right]$ & $(5)$ \\
\hline & where $f_{U}=\left(1+l_{C}\right)\left(1+l_{E}\right)\left(1+l_{F}\right)$ & $(6)$ \\
\hline \multirow[t]{2}{*}{ Conversion } & $F_{C}=M_{f} \cdot f_{C} \cdot P_{C} \cdot(1+r)^{t_{C}}$ & (7) \\
\hline & where $f_{C}=\left(1+l_{C}\right)\left(1+l_{E}\right)\left(1+l_{F}\right)$ & $(8)$ \\
\hline \multirow[t]{5}{*}{ Enrichment } & $F_{E}=\mathrm{SWU} \cdot f_{E} \cdot P_{E} \cdot(1+r)^{t_{E}}$ & (9) \\
\hline & where SWU $=M_{p} \cdot V_{p}+M_{t} \cdot V_{t}-M_{f} \cdot V_{f}$ & $(10)$ \\
\hline & $M_{t}=M_{f}-M_{p}$ & $(11)$ \\
\hline & $V_{x}=\left(2 e_{x}-1\right) \operatorname{In}\left[e_{x} /\left(1-e_{x}\right)\right]$ and $x$ is subscript for $f, p$, or $t$ & $(12)$ \\
\hline & $f_{E}=\left(1+l_{E}\right)\left(1+l_{F}\right)$ & $(13)$ \\
\hline \multirow[t]{2}{*}{ Fabrication } & $F_{F}=M_{p} \cdot f_{F} \cdot P_{F} \cdot(1+r)^{t_{F}}$ & $(14)$ \\
\hline & where $f_{F}=\left(1+l_{F}\right)$ & $(15)$ \\
\hline \multirow[t]{2}{*}{ Transport and storage } & $F_{T S}=M_{T S} \cdot f_{T S} \cdot P_{T S} \cdot(1+r)^{t_{T S}}$ & $(16)$ \\
\hline & where $f_{T S}=\left(1+l_{T S}\right)$ & $(17)$ \\
\hline \multirow[t]{2}{*}{ Disposal } & $F_{D}=M_{D} \cdot f_{D} \cdot P_{D} \cdot(1+r)^{t_{D}}$ & $(18)$ \\
\hline & where $f_{D}=\left(1+l_{D}\right)$ & (19) \\
\hline
\end{tabular}

$F_{x}$ : Cost of fuel cycle component (\$), $M_{x}$ : Mass of materials $(\mathrm{kg}), f_{x}$ : Loss factor (\%), $P_{x}$ : Unit cost (\$/unit), $l_{x}$ : Material loss (\%), $e_{x}$ : Fraction of U-235 (\%). Subscript $x$ : U: Natural uranium, C: Conversion, E: Enrichment, F: Fabrication, TS: Transportation \& storage, D: Disposal, f: Feed natural uranium (0.71\%), p: Product of uranium fuel, $t$ : Tail.

4.6. Sensitivity Analysis. This study conducted a sensitivity analysis of some unit costs in which the variability is considered large, such as the uranium price, Pyro- $\mathrm{UO}_{2}$ reprocessing, and Pyro-Metal-Fab. The break-even prices necessary for the Pyro-SFR fuel recycle to be economic compared to the OT option were also obtained by changing the input of the uranium price, Pyro-UO, and Pyro-MetalFab., respectively.

\section{Results and Discussion}

5.1. Levelized Cost of Electricity. The calculation results of the LFCC concerning these four fuel cycle scenarios show the following: OT $7.35 \mathrm{mills} / \mathrm{kWh}$, DUPIC $9.06 \mathrm{mills} / \mathrm{kWh}$, PUREX-MOX 8.94 mills/kWh, and Pyro-SFR 7.70 mills/ $\mathrm{kWh}$. The relative total costs of the fuel cycle options are presented by the bar chart in Figure 3. It shows that DUPIC, PWR-MOX, and Pyro-SFR are 23\%, 22\%, and 5\% higher than the OT option, respectively.

Figure 3 shows that the uranium price is the key cost component of the LFCC in all of these four nuclear fuel cycles. With the current uranium price, the OT is the most economical option and the Pyro-SFR is the second due to the low uranium consumption. In the Pyro-SFR scenario, the uranium consumption decreases because of the utilization of the metal fuel made from the reprocessed TRU. PyroMetal-Fab., however, makes up for the difference in uranium costs between the Pyro-SFR and OT scenarios. In the PWRMOX scenario, the uranium consumption is still high, while meanwhile the reprocessing is costly. The relative high cost of the DUPIC scenario is because of the low uranium utilization efficiency due to the low burnup and high fabrication cost required to make the PWR SF into CANDU fuel.

Generally, two decisions, that is, which kind of reactor to employ and whether or not to deploy a spent fuel treatment technology, mainly determine the direction of the nuclear fuel cycle. In this study, we focused on the impact of the introduction of spent fuel treatment technologies, that is, PUREX, DUPIC, and pyroprocessing. The introduction of reprocessing techniques in PWR-MOX and Pyro-SFR scenario do affect the back-end cost due to the recycling of $\mathrm{Pu}$ or TRU. For the DUPIC case, the treatment of spent PWR fuel for CANDU fuel plays a similar role to take advantages of residual fissile in the spent fuel. Due to the introduction of techniques to treat the PWR spent fuel, the mass flows of nuclear fuel cycles were changed accordingly. Therefore, it is informative to present the cost share of the spent fuel treatment technique in the LFCC as shown in Figure 4.

5.2. Uncertainty Analysis. The results from the Monte Carlo simulation are shown in Table 4 and Figure 5. With the assumption that each unit cost has a triangular distribution, a total of 50,000 extractions of Latin Hypercube were performed. The standard deviation (SD) for the LFCC ranges between 1.16-1.69 mills/kWh, as shown in Table 4. The difference between the LFCC of the Pyro-SFR and OT is 0.04 mills/kWh concerning the mean data, which is much smaller than the SD for the OT option, 1.69 mills/kWh. This means that the cost of the Pyro-SFR fuel recycling lies within the error bound of the direct disposal option. The costs of DUPIC and PWR-MOX also have the possibility to fall within the error bound of the OT, respectively, but their possibilities are relatively smaller. 

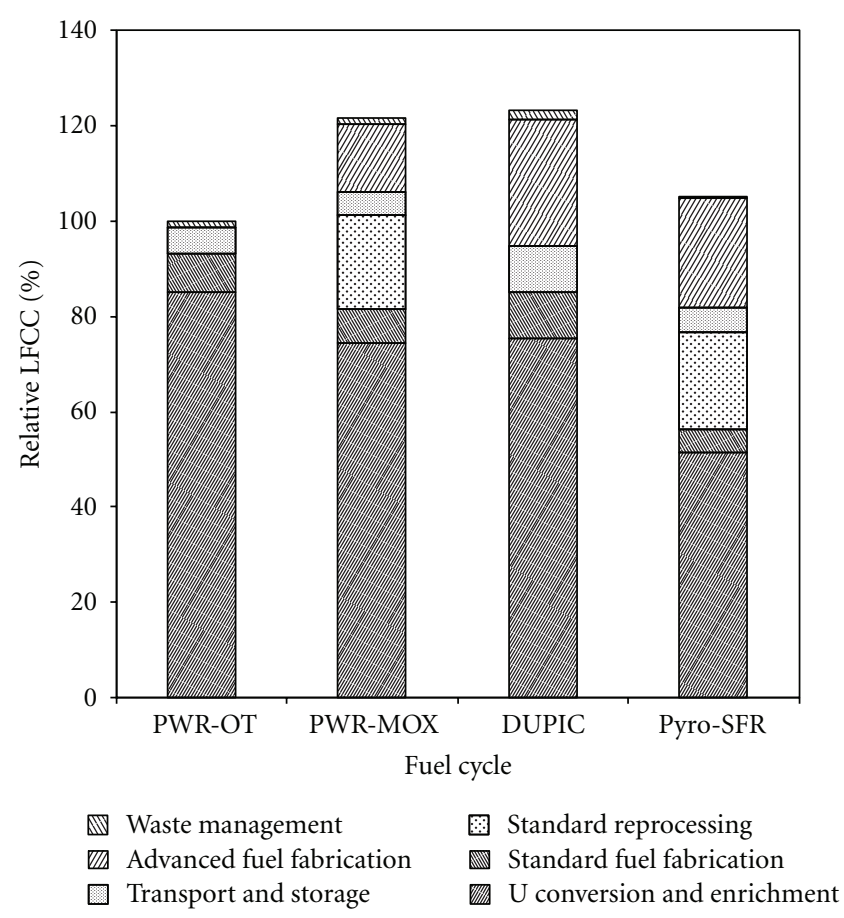

FIgURE 3: Relative LFCC of four fuel cycles.

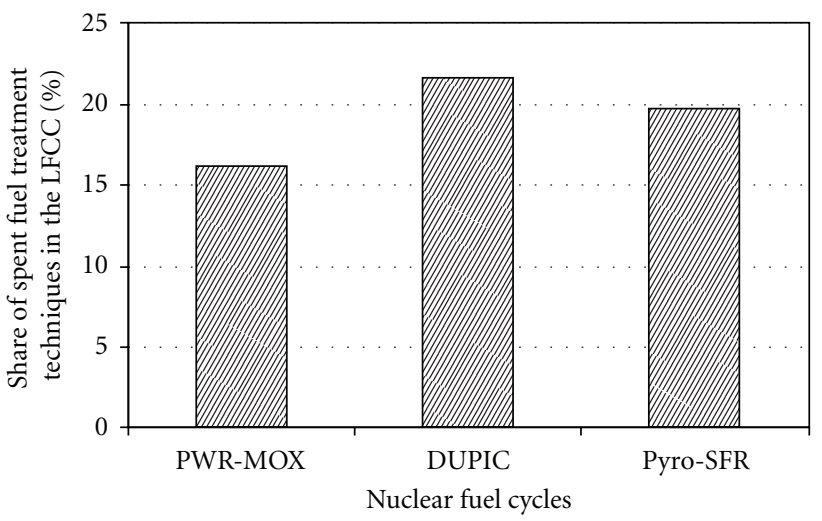

FIGURE 4: Share of spent fuel treatment techniques in the LFCC.

TABle 4: Results of a Monte Carlo simulation for the uncertainty analysis of LFCCs.

\begin{tabular}{lcccc}
\hline & OT & DUPIC & PWR-MOX & Pyro-SFR \\
\hline Min. & 3.99 & 5.68 & 5.74 & 4.51 \\
Max. & 13.79 & 15.30 & 14.77 & 12.64 \\
Mean & 8.35 & 10.06 & 9.83 & 8.31 \\
SD & 1.69 & 1.57 & 1.55 & 1.16 \\
\hline
\end{tabular}

5.3. Sensitivity Analysis. A sensitivity analysis was conducted on the key cost components, such as the uranium price, Pyro- $\mathrm{UO}_{2}$, and Pyro-Metal-Fab. Figure 6 shows the results of regression sensitivity analysis, for which a multivariate stepwise regression was applied as an analytical method for the sensitivity of multiple inputs and for deriving the regression coefficient to assess the degree of sensitivity. A

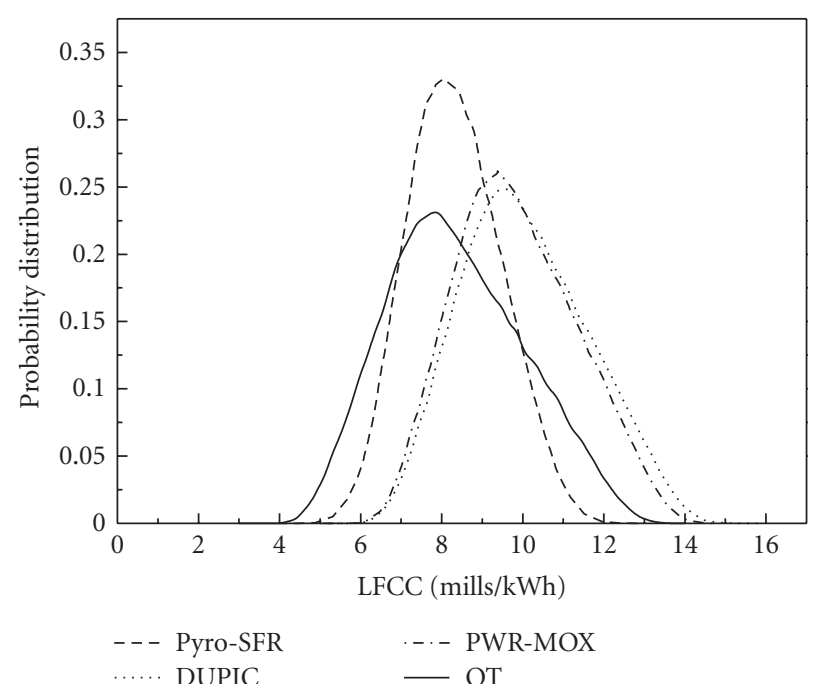

FIgURE 5: Comparison of the probabilistic density function of LFCCs using a triangular distribution.

value of 1 of the regression sensitivity means that a variation of $1 \mathrm{SD}$ for the input variable brings a variation of $1 \mathrm{SD}$ in the results. On the contrary, a regression sensitivity of 0 means that there is no influence from the input to the output.

As can be noted from Figure 6, the uranium price indicates the highest sensitivity value. It was determined that the regression coefficient of the uranium ranges from 0.95 to 0.96 for the OT, DUPIC, and PWR-MOX options. However, the coefficient of the Pyro-SFR fuel recycle, 0.85, shows a lower sensitivity of the uranium price compared to other fuel cycle options. While another high sensitivity factor is shown to be the uranium enrichment in the OT and PWR-MOX scenarios. In the Pyro-SFR option, Pyro- $\mathrm{UO}_{2}$ and PyroMetal-Fab. show higher sensitivities.

5.4. Break-even Uranium Price. Since uranium is the main driver of the LFCC, a fluctuation of uranium price influences the total cost considerably. The historical data of uranium price, however, changed dramatically, and it is challenging to predict the future uranium price. A large range of uranium prices is therefore adopted to find out at which price level the recycled fuel cycle options will be more economical than the OT option, or at which level they will break even.

The sensitivity analysis on the uranium price shows that the OT option depends more on the cost of uranium than on any other fuel cycle options (Figure 6 and Figure 7), which could be explained by the largest amount of uranium consumed for producing a given quantity of energy. PyroSFR, however, is much less sensitive to the uranium price indicated by a smaller slope in Figure 7. By increasing the uranium price, the LFCC of the OT option finally reaches and surpasses those of Pyro-SFR and PWR-MOX, respectively, due to the different weight of uranium cost in each cycle scheme.

A break-even price is defined to specify the price at which the LFCC of the OT equals the LFCC of another fuel cycle 


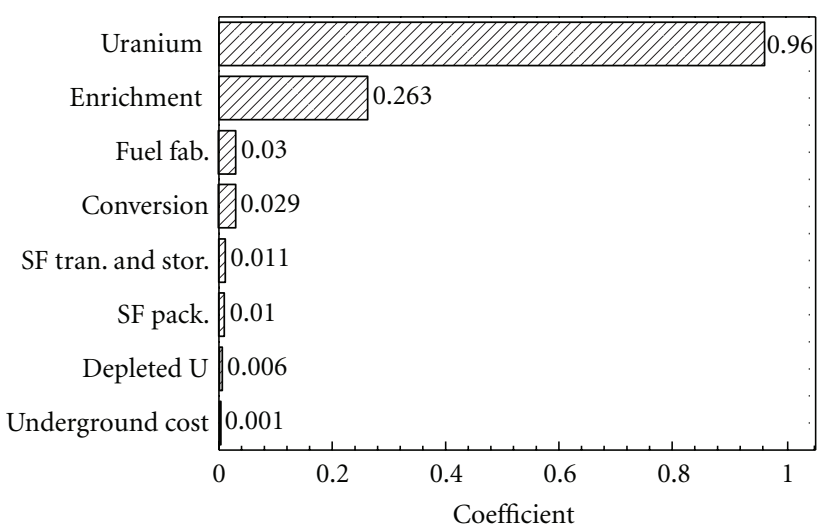

OT

(a)

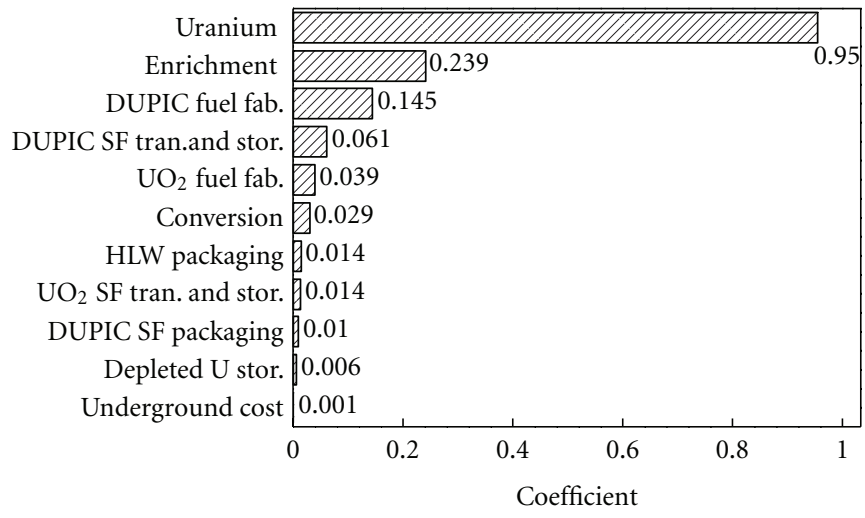

DUPIC

(c)

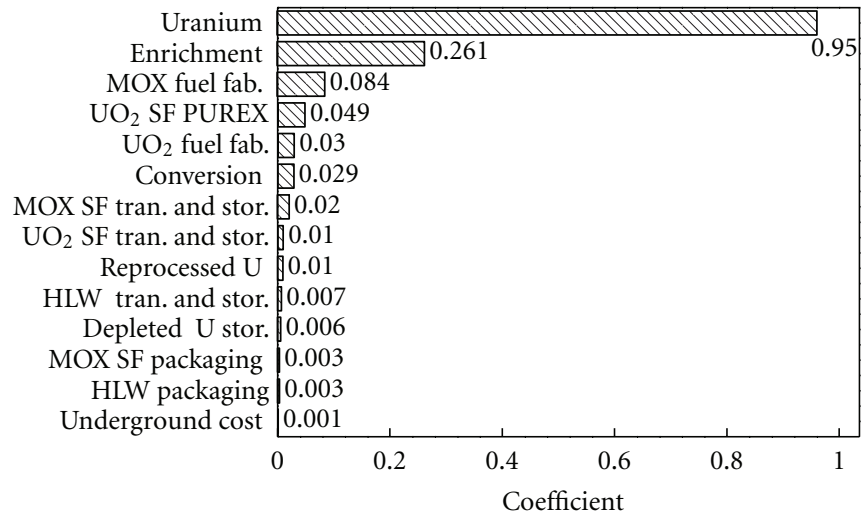

PWR-MOX

(b)

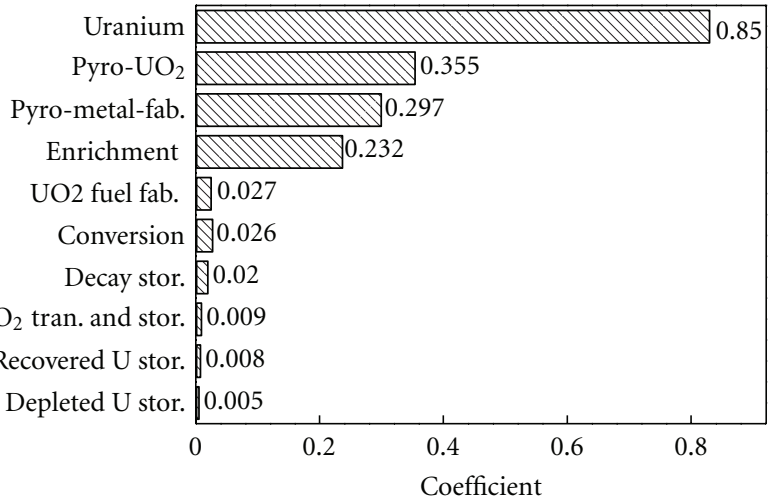

Pyro-SFR

(d)

Figure 6: Sensitivity coefficient of fuel cycle components.

option. The calculation of uranium break-even price is a kind of sensitive analysis. By setting the input unit costs fixed and only changing the uranium unit price, a unit price of uranium can be derived at which the LFCC cost of a specific nuclear fuel cycle equals to the LFCC of OT. However, it should be noted that the calculation was based on the reference unit cost listed in Table 2. Even the nominal data have unavoidably uncertainty and that is why a cost scale is associated with each unit cost. However, the nominal data is currently highly reliable, and the purpose of calculating the break-even price is to indicate a potential trend not to offer a precise and exact data, so the use of the nominal data for discount rate sensitive analysis is reasonable.

The break-even price of uranium was calculated to be $800 \$ / \mathrm{kgU}$ for PWR-MOX fuel cycle and $215 \$ / \mathrm{kgU}$ for PyroSFR fuel cycle with reference to the OT option. The actual price of uranium in July 2007 recorded $350 \$ / \mathrm{kgU}$, which is 13 times higher than that of 2001. If Pyro-SFR was available as of 2007 peak in uranium price, its nongeneration fuel cycle costs would have been competitive with those of the OT. The gap of LFCCs between the Pyro-SFR and OT still exists at the current uranium price. The amount of uranium with an acceptable price, however, is definitely decreasing, and the nuclear power capacity in East Asia is increasing dramatically at the same time. According to this trend, the higher uranium consumption efficiency a nuclear fuel cycle pursues the better competitiveness it may obtain.

5.5. Break-even Uranium Price Dependent on Pyrotechniques. With regard to a potential cost decrease of certain components, it is of great interest to analyze the influence of the changes of fuel cycle components on the LFCCs, especially focusing on the cost of Pyro- $\mathrm{UO}_{2}$ and Pyro-metal-Fab., respectively.

Pyro- $\mathrm{UO}_{2}$ and Pyro-Metal-Fab. are currently under development, and there is no industrial experience worldwide yet. The cost data concerning those unavoidably maintain a high uncertainty. Pyro- $\mathrm{UO}_{2}$ and Pyro-Metal-Fab. contribute heavily to the LFCC of Pyro-SFR recycling by changing the cost of each pyrotechnique, and it is therefore possible to estimate the sensitivity of the break-even uranium price of the Pyro- $\mathrm{UO}_{2}$ and Pyro-metal-Fab. compared with OT, as shown in Figure 8. When the cost of Pyro- $\mathrm{UO}_{2}$ equals to the cost of PUREX, or around $50 \%$ of the nominal unit cost, the break-even price of uranium is around $125 \$ / \mathrm{kgU}$. This means when the cost of Pyro- $\mathrm{UO}_{2}$ becomes equal to 


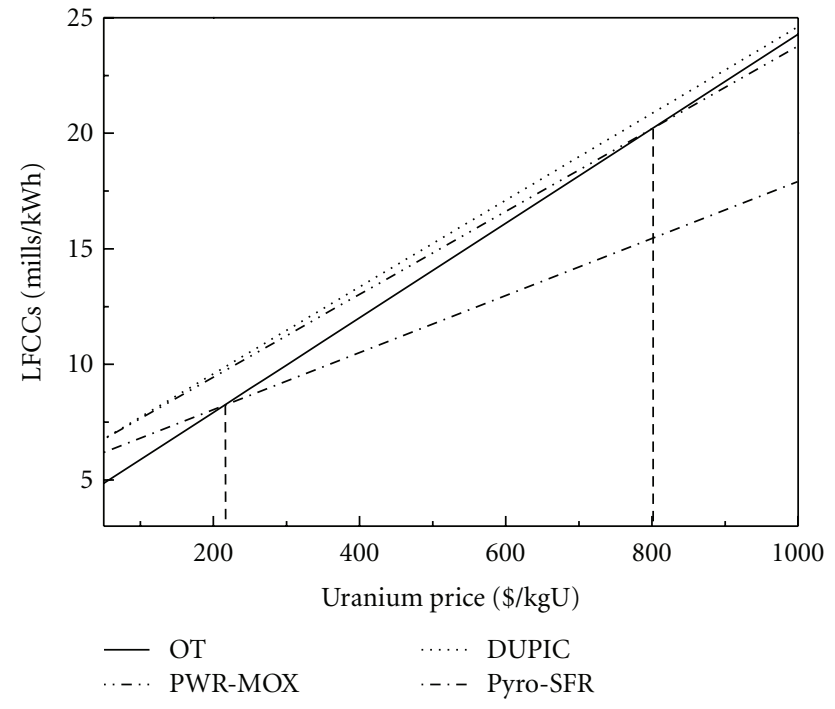

Figure 7: LFCCs dependent on the uranium price.

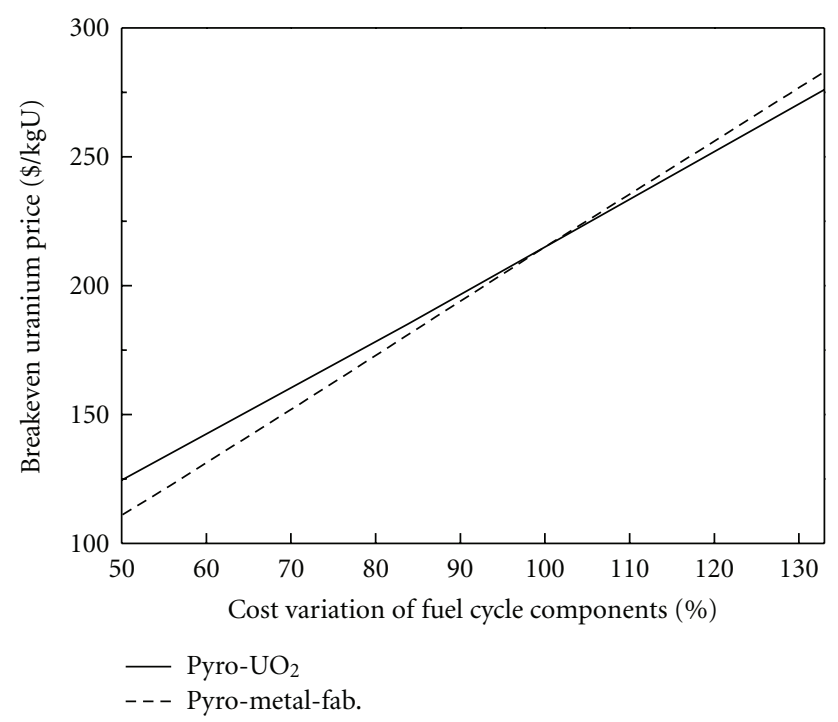

FIGURE 8: Break-even uranium price dependent on pyrotechniques.

the cost of PUREX, the LFCC of Pyro-SFR cycle can become the same as the LFCC of the OT with a uranium price of $125 \$ / \mathrm{kgU}$. If the unit cost of Pyro-Metal-Fab. decreases by $50 \%$ of the current nominal unit cost, the break-even price of uranium is around $110 \$ / \mathrm{kgU}$ by reaching which the LFCC of Pyro-SFR and LFCC of OT become the same value. The research and development of pyrotechniques may offer a promising economic advantage to Pyro-SFR over the others.

5.6. Sensitivity Analysis of Pyro-UOH $\mathrm{U}_{2}$ and Pyro-Metal-Fab. The sensitivity analysis was also performed on the key components of Pyro-SFR with comparatively high uncertainty at the current price. For instance, the reference unit cost of $1500 \$ / \mathrm{kgHM}$ for Pyro- $\mathrm{UO}_{2}$ and $5000 \$ / \mathrm{kgHM}$ for PyroMetal-Fab., as quoted from the AFCCI report, was deemed

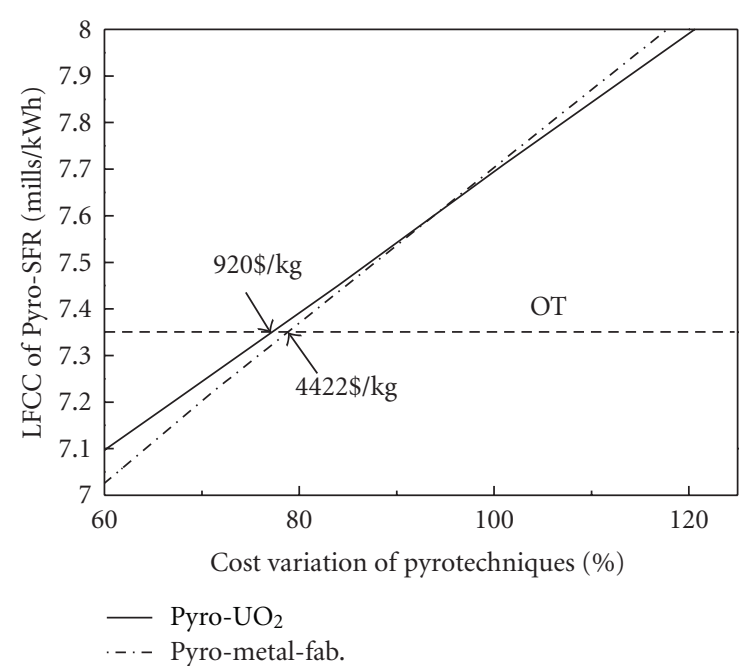

FIGURE 9: LFCC of Pyro-SFR dependent on the cost of pyrotechniques.

to be a bit too high by some commentators, in view of the possible decrease by research and development.

The break-even price of Pyro- $\mathrm{UO}_{2}$ with reference to the OT option was evaluated to be $920 \$ / \mathrm{kgHM}$, which is around $61 \%$ of the nominal cost, as shown in Figure 9. This calculation was performed by varying the Pyro- $\mathrm{UO}_{2}$ costs, while all other costs were fixed to their reference values until the equalization with that of the OT cost was achieved.

The break-even price of Pyro-Metal-Fab. was calculated to be $4422 \$ / \mathrm{kgHM}$, which is around $88 \%$ of the nominal cost, as shown in Figure 9. This break-even price is 18 times higher than the nominal cost of uranium fuel fabrication, which indicates that a promising price decrease may be realized by research and development.

\section{Conclusion}

The economics of OT, DUPIC, PWR-MOX, and PyroSFR fuel cycle scenarios have been calculated and compared by employing an equilibrium model. LFCCs were obtained for a fair comparison: OT 7.35 mills/kWh, DUPIC 9.06 mills/kWh, PUREX-MOX 8.94 mills/kWh, and PyroSFR 7.70 mills/kWh. The uranium price in the four scenarios generally acts as the dominant driver of LFCCs. Pyrotechniques also weigh considerably in the Pyro-SFR scenario. In consideration of the current unavoidable uncertainties introduced by certain cost data, a cost range and the triangle techniques were used to perform an uncertainty study, which indicates that the gap between the Pyro-SFR and OT fuel cycle scenarios is relatively smaller than the other options.

Also, the sensitivities of uranium, Pyro- $\mathrm{UO}_{2}$, and PyroMetal-Fab. were carried out to determine the potential advantages of the Pyro-SFR scenario. The break-even price of uranium for a Pyro-SFR was obtained by an increase in the uranium price within a large range, and the breakeven price was $215 \$ / \mathrm{kg}$ for Pyro-SFR and $800 \$ / \mathrm{kg}$ for PWRMOX. With regard to the uranium historical peak price in 
2007, it may be worth deploying Pyro-SFR in the foreseeable future. The influences of pyrotechniques on the LFCC of the Pyro-SFR were carried out to clarify the targets for current immature technologies. If the current uranium price remains stable, the break-even price for Pyro- $\mathrm{UO}_{2}$ is $920 \$ / \mathrm{kgHM}$ and $4422 \$ / \mathrm{kgHM}$ for Pyro-metal-Fab., respectively, which are actually close to the nominal costs employed.

In conclusion, the difference in the fuel cycle costs between the Pyro-SFR and OT fuel cycle is negligible, considering the uncertainty associated with the unit cost of the fuel cycle components. Therefore, other factors such as technological and political risks, environmental effects, public acceptability, and nonsproliferation, could play important roles in determining the future nuclear fuel cycle options.

\section{Acknowledgments}

This project has been carried out under the Nuclear R\&D Program funded by the Ministry of Education, Science, and Technology of Korea.

\section{References}

[1] OECD/NEA, The Economics of the Nuclear Fuel Cycle, OECD, Paris, France, 1994.

[2] B. Dixon, W. Halsey, S. Kim, G. Matthern, S. Piet, and D. Shropshire, Dynamic Systems Analysis Report for Nuclear Fuel Recycle, INL/EXT-08-15201 Rev.1, 2008.

[3] Economic Analysis Working Group. AFCI Economic Tools, Algorithms, and Methodology, INL/EXT-07-13293, 2009.

[4] J. M. Deutch and J. P. Holdren, The Future of Nuclear Power: An Interdisciplinary MIT Study, Massachusetts Institute of Technology, Cambridge, Mass, USA, 2003.

[5] OECD/NEA, Advanced Nuclear Fuel Cycles and Radioactive Waste Management, NEA No. 5990, OECD, Paris, France, 2006.

[6] W. I. Ko, J. W. Choi, J. S. Lee, H. S. Park, and K. J. Lee, "Uncertainty analysis in DUPIC fuel-cycle cost using a probabilistic simulation method," Nuclear Technology, vol. 127, no. 1, pp. 123-140, 1999.

[7] S. G. Hong et al., "600 MWe sodium cooled fast reactor core designs for efficient TRU transmutation," The Korean Nuclear Society Spring Meeting, Chuncheon, Korea, May 2006.

[8] T. Inoue, "Actinide recycling by pyro-process with metal fuel FBR for future nuclear fuel cycle system," Progress in Nuclear Energy, vol. 40, no. 3-4, pp. 547-554, 2002.

[9] B. H. Park, F. Gao, E. H. Kwon, and W. I. Ko, "Comparative study of different nuclear fuel cycle options: quantitative analysis on material flow," Energy Policy, vol. 39, no. 11, pp. 6916-6924, 2011.

[10] M. Bunn, J. P. Holdren, S. Fetter, and B. Van Der Zwaan, "The economics of reprocessing versus direct disposal of spent nuclear fuel," Nuclear Technology, vol. 150, no. 3, pp. 209-230, 2005.

[11] OECD/NEA, Accelerator-Driven Systems (ADS) and Fast Reactors (FR) in Advanced Nuclear Fuel Cycles, OECD, Paris, France, 2002.

[12] OECD, Cost Estimating Guidelines for Generation IV Nuclear Energy Systems, OECD, Paris, France, 2006.

[13] OECD, Trends in the Nuclear Fuel Cycle: Economic, Environment and Social Aspects, OECD, Paris, France, 2000.
[14] D. Shropshire et al., Advanced Fuel Cycle Cost Basis, INL/EXT07-12107, 2007.

[15] D. Shropshire et al., Advanced Fuel Cycle Cost Basis, INL/EXT07-12107 Rev.1, 2008.

[16] D. Shropshire et al., Advanced Fuel Cycle Cost Basis, INL/EXT07-12107 Rev.2, 2009.

[17] The Ux Consulting Company, Weekly spot $\mathrm{Ux}_{3} \mathrm{O}_{8}$ price, 2010, http://www.uxc.com/review/uxc_Prices.aspx.

[18] W. I. Ko, H. Choi, and M. S. Yang, "Economic analysis on direct use of spent pressurized water reactor fuel in candu reactors-IV: DUPIC fuel cycle cost," Nuclear Technology, vol. 134, no. 2, pp. 167-186, 2001.

[19] W. I. Ko, J. W. Choi, C. H. Kang, J. S. Lee, and K. J. Lee, "Nuclear fuel cycle cost analysis using a probabilistic simulation technique," Annals of Nuclear Energy, vol. 25, no. 10, pp. 771-789, 1998. 

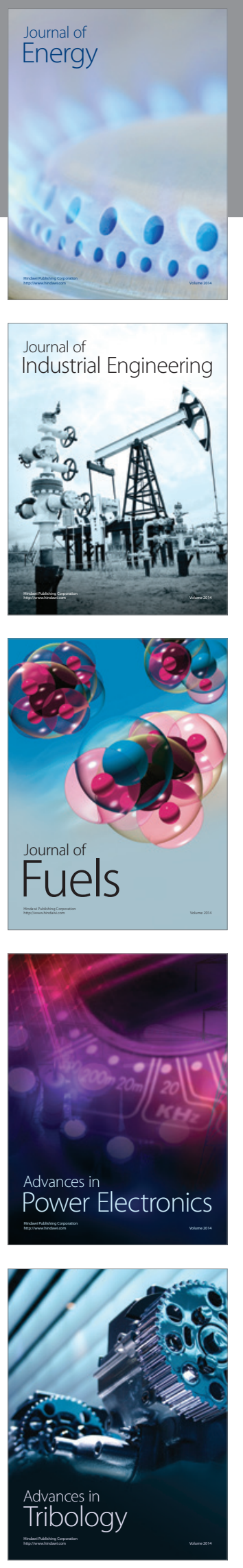
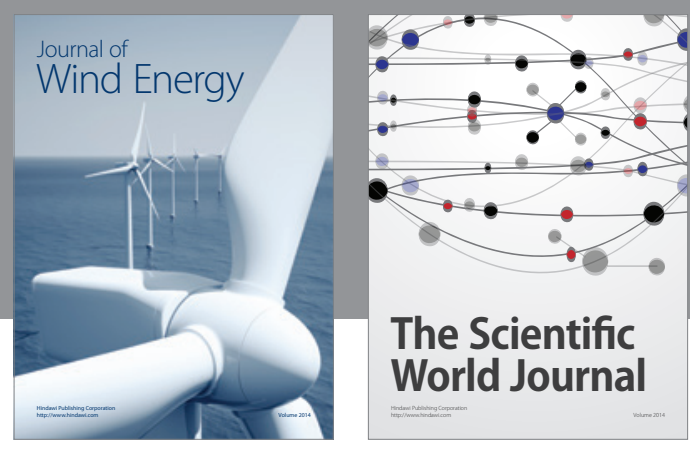

The Scientific World Journal

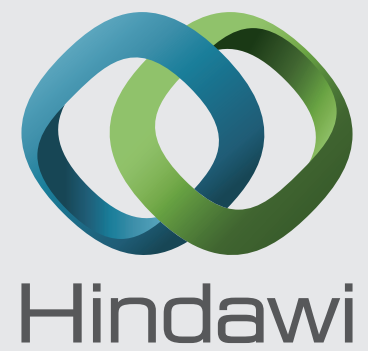

Submit your manuscripts at http://www.hindawi.com
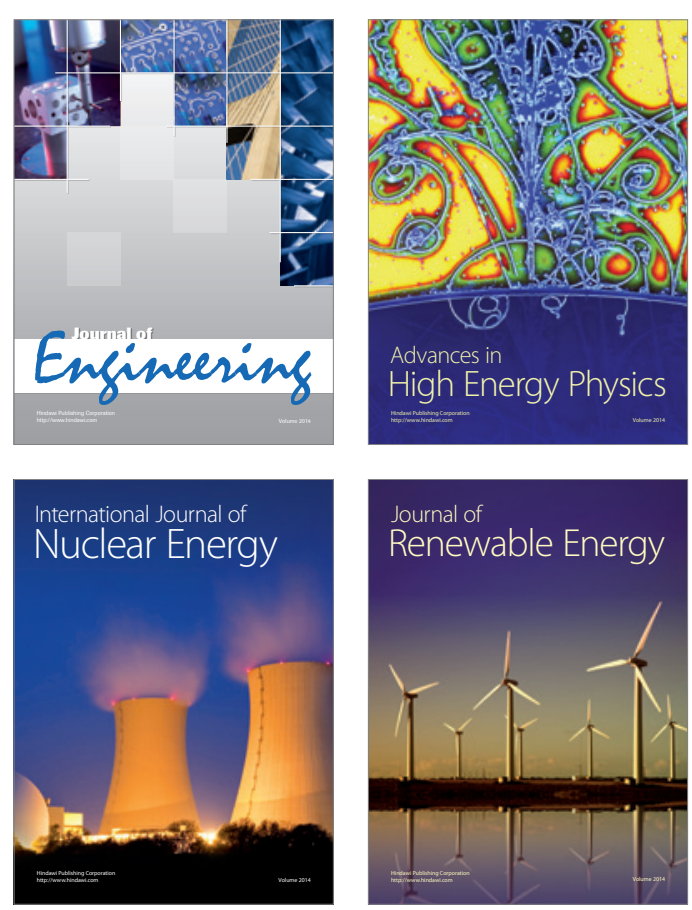

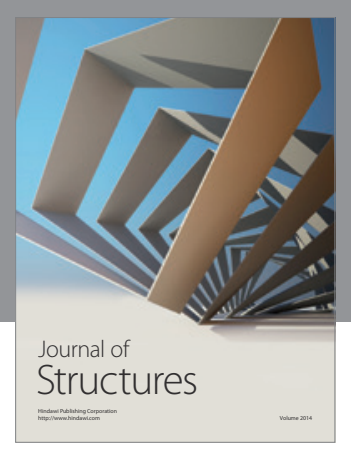

Rotating
Mechinery
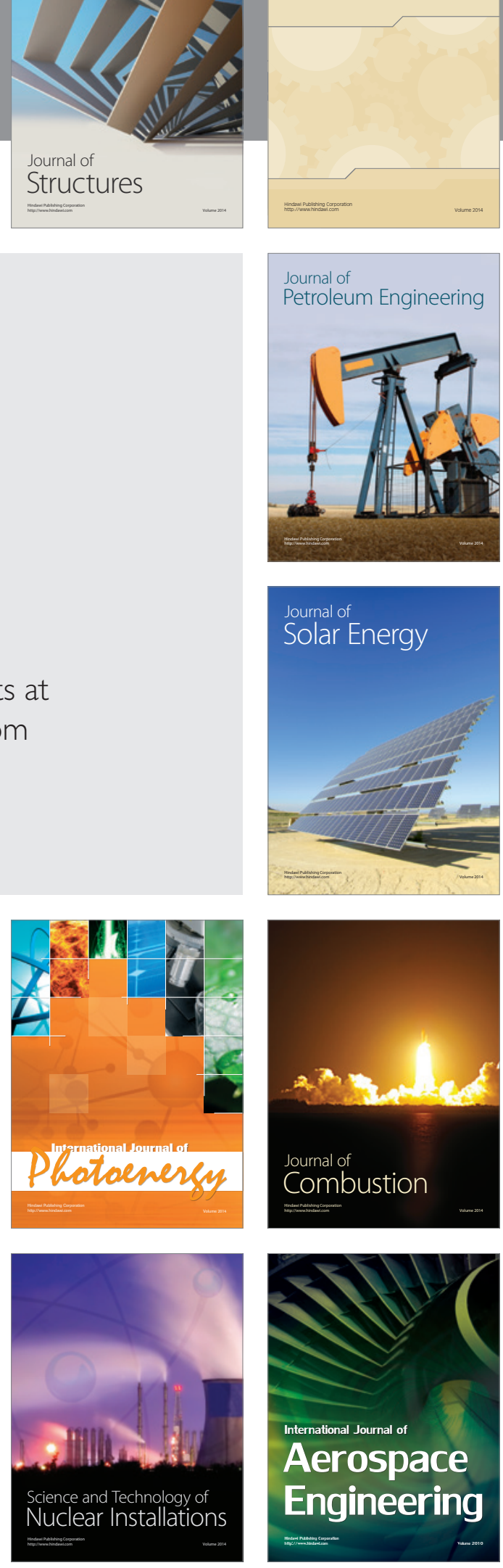